\title{
Rice Bran Oil- A Silver Lining to Indian Edible Oil Economy: A Review
}

\begin{abstract}
Edible oil is an integral part of everyday cooking, due to remarkable gain in vegetable oil consumption in India over the past few decades. Accomplishing edible oil requirement of the ever-growing population is a formidable task before the country. On the contrary, annual compound growth rate of major edible oilseeds in India is declining. This phenomenal disparity in demand and supply of vegetable oil in the country is tending to bother through profuse investment on overseas purchase. At this point of time, in order to meet on-growing demand of edible oil, rice bran oil can be the available option before the country. India being the major producer of rice, yields significant amount of bran which contain upto $24 \%$ edible grade superior quality vegetable oil. It essentially contains $48.48 \%$ oleic acid, $35.26 \%$ linoleic acid, $14.54 \%$ palmitic acid, $8.15 \%$ free fatty acid besides contain good number of antioxidants such as tocopherols, tocotrienols and oryzanol. Therefore, rice bran oil became the integral part of oil market in India and abroad. Inspite of its benefits, it has not been fully exploited. If its potentiality is harnessed completely, rice bran oil could emerge as silver lining of Indian edible oil economy.
\end{abstract}

Key words: Economy, Edible oil, India oilseeds, Prospects, Rice bran oil.

In India rice is not just a crop, it's country's economy. India is the world's second largest producers of rice with approximately 43 million hectare planted area, accounting for $22 \%$ of the world's rice production, it is mostly grown in the eastern and southern parts of the country. Rice being member of tropical $\mathrm{C}_{3}$ plant it flourishes well in hot and humid climate. In India rice is mainly grown under rainfed situation where annual rainfall is ranges from $1000-2500 \mathrm{~mm}$. Therefore, it is fundamentally grown as kharif crop in India however, it is also being cultivated in rabi and summer season based on the water availability. If we see the journey of rice around the world, it has been slow, but if it establishes its roots, crop stayed and became integral part of agriculture and economy of that locality. In the Indian subcontinent, more than a quarter of the cultivated land is under the rice crop. It makes essential part of the daily meal in the southern and eastern parts of India, whereas in the northern and central India, wheat is common food stuff, nevertheless, rice holds its own importance and is cooked daily at least once. Hence, demand for rice is increasing year after year. At present, rice is being grown in 43.79 million hectare and producing 117.47 million tons annually with the average productivity of $2578 \mathrm{~kg} / \mathrm{ha}$ (GOI, 2020). Milling is a crucial step in post-production of rice. The basic objective of rice milling system is to remove the husk and the bran layers, and produce an edible, white rice kernel that is sufficiently free from impurities. Rice being the indispensable source of energy to the huge group of Indian population, upon it milling we also generate huge amount of rice bran. Based on the country's paddy production, rice bran output potential is about 9.8 million tonnes annually (Solvent Extractors' Association, 2019), However, at present India is processing only 5 million tonne out of 9.8 million tonnes which is just half of its total potentiality and the rest is consumed directly
All India Co-ordinated Research Project on Castor, Zonal Agricultural Research Station, University of Agricultural Sciences, Bangalore-560 065, Karnataka, India.

Corresponding Author: R Mohan Kumar, All India Co-ordinated Research Project on Castor, Zonal Agricultural Research Station, University of Agricultural Sciences, Bangalore-560 065, Karnataka, India.mohanomkey@gmail.com

How to cite this article: Kumar, R.M., Yamanura and Boraiah, B. (2021). Rice Bran Oil- A Silver Lining to Indian Edible Oil Economy: A Review. Agricultural Reviews. DOI: 10.18805/ag.R-2140.

Submitted: 25-11-2020 Accepted: 17-03-2021 Online: 29-04-2021

as cattle feed. The rice bran oil production potential is over 1.62 million tonnes per annum in India as against untapped potential of nearly 6.5 tonnes (Solvent Extract Association, 2019). However, a study conducted by Zúñiga-Diaz et al. (2017) for quality profiling of rice bran oil indicated that, rice bran has $21.44 \%$ of raw oil, with a chemical composition of $48.48 \%$ oleic acid, $35.26 \%$ linoleic acid and $14.54 \%$ palmitic acid, as well as a free fatty acid content of $8.15 \%$. On the other side if we see the scenario of vegetable oilseeds in India, Oilseed crops stands next to the cereals and plays a key role in deciding agricultural economy. The so called "Yellow Revolution" happened during 1986-87 brought selfsufficiency in oilseeds but was not sustained for a longer period of time. This could be due to huge gain in population followed by tremendous shift in the fat consumption pattern (Fig 1). At present, India need to produce about 25 million tonnes of edible oils to meet its domestic requirement at the current consumption level of $19.4 \mathrm{~kg}$ per (GOI, 2020).

This indicates there is a pressing need to mobilize more vegetable oils into domestic market to meet out ever- 


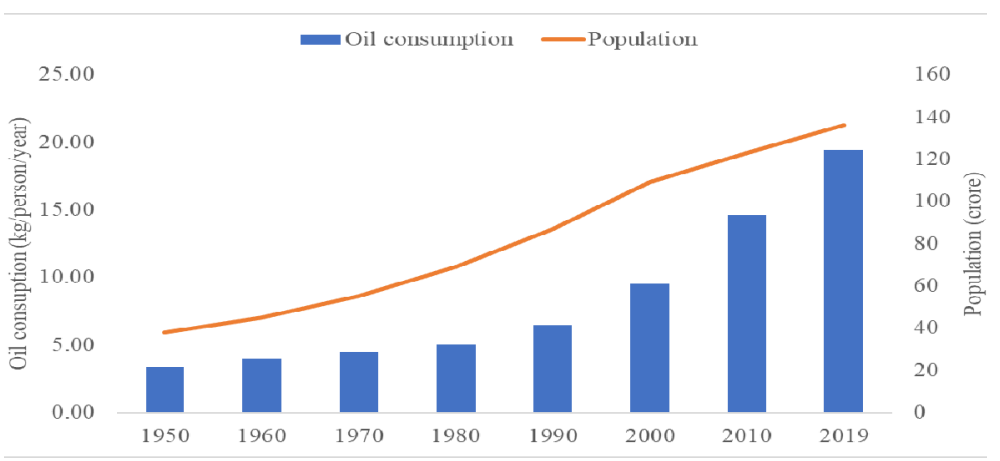

Source: Ministry of Agriculture (2018).

Fig 1: Vegetable oil consumption pattern in India.

growing demands. It is unfortunate that, despite India being the fifth largest oilseed crop producing country in the world, it is also the largest importer of vegetable oils today (GOI, 2020). Currently, India spends about Rs. 73,048 crores to import 60 per cent of vegetable oil consumed annually to meet out its domestic demand (NMOOP, 2018) and is increasing exponentially on account of increasing population and living standards. On the other end, declining growth rates of all annual edible oilseed crops during the past decade is poor (negative for area and production) especially in major oilseeds crop such as sunflower, safflower, linseed, niger and negative for area in groundnut (NMOOP, 2018). However, soybean and castor crops are steadily emerging as ray of hope by registering positive and high growth rates but castor is non-edible oilseed crop. Further, rapeseed-mustard also registered higher growth rate of production (Table 1). In this scenario of uncertainty of oilseeds production, there is a pressing need on the country to explore all possible sources of edible oils to sustain its vegetable oil economy to curtail the investment on imports. In this view, lot of attention is being diverted to explore the opportunities of non-traditional oilseeds to meet out vegetable oil demand in the country, but most of the non-traditional oilseeds yield a characteristic dark color and possess unpleasant smell and non-lipid constituents. These problems are aggravated by the hostile conditions during collection in the forests, storage and subsequent processing. Inspite of that, rice bran is one such commodity mostly going as a waste during milling of paddy (Fig 2) and this could be considered as an opportunity to sustain the growing needs of edible oil. India being the country with global stewardship in rice production, after processing the left-out bran yield, the miracle product called rice bran oil. The rice bran oil is popularly termed as a "wonder oil" as it provides numerous health benefits upon consumption. Nayik et al. (2015) opined that, rice branoil has a number of health benefits over other edible oils because of unique antioxidant known as oryzanol. It is a rich source of $\mathrm{Y}^{-}$ oryzanol, tocopherols, tocotrienols and sterols (Dunford and King, 2000). Further, Ju and Vali, (2005) reported that, the crude rice bran oil contains about $1.1-2.6 \%$ of $\mathrm{y}$-oryzanol,
$0.2 \%$ of tocopherols, $70 \%$ of which is tocotrienol and 3 $5 \%$ of phytosterols and fatty acids steryl esters. Rice being an oldest cultivated crop it has diverse array of cultivars, hybrid and varieties under cultivation, and depending on the variety, rice bran contains $10-26 \%$ oil (Chatha et al., 2011). After the milling process, to extract the rice barn oil, it needs to undergo a process called stabilization to inactivate the enzymes and inhibit lipid oxidation (Garba et al., 2017). This process is essential to prevent the deterioration of fat and valuable bioactive compounds of the bran (Loypimai et al., 2015). Several workers have given varieties of oil stabilization for rice bran. Among them, steaming and ohmicheating (Lakkakula et al., 2004, Matouk et al., 2009 and Loypimai et al., 2015), ultrasound treatment (Huang et al., 2013, Sayasoonthorn et al., 2012); parboiling, refrigeration and $\mathrm{pH}$ lowering (Amarasinghe et al., 2009) and microwave radiation (Uquiche et al., 2008). India is the global leader in rice bran oil production followed by Japan, Thailand and China (Solvent Extract Association, 2019). At present, the global rice bran oil market size was valued at USD 4.04 billion and is expected to register a compound annual growth rate of $3.44 \%$ from 2019 to 2025 (Market Analysis Report, 2019). The annual production of rice bran oil market is tremendously increasing with about 50 thousand tons per annum, which could be due to growing interest on health and high cost of animal fat in developing and under developed countries. Therefore, this is the high time to focus ourselves in devising suitable strategies to explore this untapped reservoir of rice bran oil in India to reduce pressure on rainfed agro-ecosystems as oilseeds crops are imperative members of rainfed cropping systems. In this context, this paper review throws some light on present status and way forward to achieve self sufficiency in edible oil.

\section{Scope for rice bran oil}

According to World Health Organization (WHO) definition of Health, it is a state of mental, physical and social wellbeing and not merely the absence of any disease or infirmity". Food matters a lot for healthy life. Cooking oil is a vital and 
basic part of Indian diets. According to the latest recommendations by National Institute of Nutrition (NIN) and Indian Council of Medical Research (ICMR) the ideal fatty acid composition of an edible oil and an oil is said to be balanced and suitable for consumption when it contains an average $27-33 \%$ of saturated fatty acids, $33-40 \%$ of monounsaturated fatty acids and $27-33 \%$ of polyunsaturated fatty acids. If we see the quality profiling of rice bran oil, it is closest to the recommendation made by NIN and ICMR as it contains an average percentage of saturated fatty acids $(24 \%)$, monounsaturated fatty acids $(42 \%)$ and polyunsaturated fatty acids $(34 \%)$. The data presented in the Table 3 gives an over view of rice bran oil with regards to its quality parameters. In addition to ideal fatty acid profile, rice bran oil also contains good and diverse load of natural oxidants which are required for human body. Hence, it is considered as "Functional Food" or a "Health Food" in Western Countries.

Based on varieties of health benefits of rice bran oil, it is extensively used as a premium edible oil in most of the Asian counties like Japan, Korea, China, Taiwan and Thailand (Garba et al., 2017). Especially in Japan, due to its diverse cardiovascular benefits it is popularly termed as

Table 1: Growth in XII Plan over XI Plan.

\begin{tabular}{lccc}
\hline \multirow{2}{*}{ Crops } & \multicolumn{3}{c}{ Per cent increase/decrease } \\
\cline { 2 - 4 } & Area & Yield & Production \\
\hline Castor & +11.10 & +16.00 & +27.00 \\
Linseed & +11.10 & +20.80 & -7.72 \\
Niger & -29.58 & +15.10 & -18.80 \\
Groundnut & -14.00 & +13.40 & -2.44 \\
Sesame & -7.70 & +13.50 & +5.00 \\
Rapeseed and Mustard & +0.23 & +7.20 & +7.40 \\
Soybean & +18.00 & -10.00 & +6.24 \\
\hline
\end{tabular}

Source: NMOOP, Ministry of Agriculture (2018).
'Heart Oil' (Nayik et al., 2015). Deep frying is the most common observed method of cooking in most of the food stuffs. In such situation, rice bran would be the suitable choice of oil as it is more stable at higher temperature, gives better taste and flavour to foods (Garba et al., 2017). Upon frying food stuffs with rice bran oil $15 \%$ less oil is used as it assures edible oil economy at household level (Fan et al., 2013). Further, it was also observed by Sharma (2002) that rice bran oil was highly suitable for high temperature cooking as it gives high smoke point of $254^{\circ} \mathrm{C}$ and mild flavour. Based on its diverse benefits in diverse cooking pattern, the oil is currently used in snacks food industries and restaurants due to its stability at high cooking temperatures and better flavour characteristics and also relished by the customers. According to recent reports on cooking oil usage, about onethird of all Japanese restaurants in US have shifted to the rice bran oil in the recent past (Sharma, 2002). Presently, extraction and utility of rice bran oil has taken new dimension as well beside used as cooking oil, market strength of rice bran oil has widened due to its utilization in specialty ingredients in the cosmetic or personal care market. The chemical compositions of rice bran oil are used in manufacturing varieties of cosmetics such as sunscreen lotions, nail polishes, lipsticks and hair conditioners (Garba et al., 2017), hair growth and prevent aging (Bernardi et al., 2011) and skin softening and repair (Patel and Naik, 2004). Based on it's identified benefits in food and nonfood purpose it could be used as potential substitutes for other oilseeds crop in production of vegetable oil.

\section{Present status of rice bran oil}

Rice is the life line of Indian farming, though rice is an aquatic plant fits well under diverse growing condition ranging from deep submergence to the semi-arid and arid condition with specialized crop establishment methods. It is observed that, inspite of fluctuation in area, rice exhibits steady increase in production (Fig 3). On the contrary, declining the growth

Table 2: Fatty acid profile of rice bran oil in comparison with other edible oils.

\begin{tabular}{|c|c|c|c|c|c|}
\hline Recommendation & $\begin{array}{c}\text { SFA } \\
27-33 \%\end{array}$ & $\begin{array}{c}\text { PUFA } \\
27-33 \%\end{array}$ & $\begin{array}{c}\text { MUFA } \\
33-40 \%\end{array}$ & $\begin{array}{c}\text { Omega } 6 / \\
\text { omega } 35-10 \%\end{array}$ & $\begin{array}{c}\text { Natural } \\
\text { antioxidant }\end{array}$ \\
\hline Ghee & 67 & 03 & 30 & 2 & - \\
\hline Vanaspathi & 60 & - & 40 & - & - \\
\hline Palm oil & 50 & 10 & 40 & - & Tocopherols \\
\hline Sunflower oil & 12 & 69 & 19 & 68 & Tocopherols \\
\hline Soybean & 15 & 61 & 24 & 08 & Tocopherols \\
\hline Corn oil & 13 & 59 & 28 & 58 & Tocopherols \\
\hline Cotton seed oil & 26 & 55 & 19 & 54 & Tocopherols \\
\hline Mustard oil & 03 & 29 & 68 & 1 & Tocopherols \\
\hline Olive oil & 16 & 11 & 73 & 10 & Tocopherols \\
\hline Groundnut oil & 22 & 33 & 45 & 32 & Tocopherols \\
\hline Rice bran oil & 22 & 35 & 43 & 22 & $\begin{array}{l}\text { Tocopherols, } \\
\text { tocotrienols } \\
\text { and oryzanol }\end{array}$ \\
\hline
\end{tabular}

Source: NIN-WHO Workshop, Hyderabad (2005). 
rates of major oilseeds crop over the period of time (Table 2) besides significant gain in the fat consumption pattern in the country is alarming (Table 1). Due to this, there is a huge pressure on country to explore possible sources of vegetable oil. In order to avoid huge foreign investment, rice bran is one such by product of rice industry otherwise going as a waste depending on the variety rice branand yield about $10-26 \%$ oil of superior edible grade oil (Chatha et al., 2011). Rice is the staple food crop for more than $70 \%$ of Indian population (Mahajan et al., 2012) therefore sustainable rice production is inevitable for the country like India (Gill and Jat, 2006). Under such situation, sustained availability of raw material in production of rice bran oil is added advantage. Hence, there is a huge scope in India to take best possible advantages of rice bran. As per the recent reports of Solvent Extractors' Association (2019) India is the world's second largest producer of rice and it is the most important cereal food crop in the country. Based on the country's paddy production, rice bran output potential is about 9.8 million tonnes. However, as of now, India is having infrastructure to process only 5 million tonne and the rest is consumed directly as cattle feed otherwise going as a solid waste. Based on available rice bran, oil production potential of rice bran oil is about 1.62 million tonnes per annum as against the untapped potential of 6.50 million tonnes (Solvent Extractors' Association, 2019).

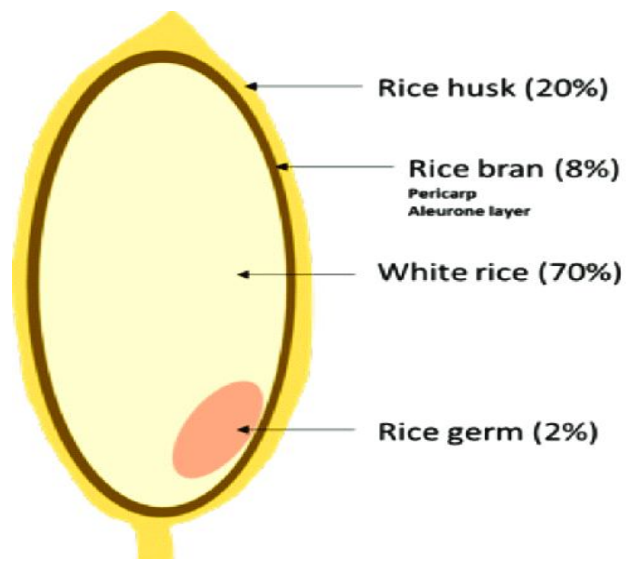

Fig 2: Pictorial representation of bran portion of paddy.
In India, full potential of rice bran oil is not tapped. Further, it was observed that, global rice bran oil market size is swelling day by day, India rice bran oil market size was valued at over 600 million USD in 2014 and by the end of 2019 the rice bran oil was valued at 1170 million USD and is expected to grow at a CAGR (expand) of roughly $3.0 \%$ over the next five years, will reach 1390 million USD in 2024 (Global Rice Bran Oil Market Report, 2020). This enormous gain in rice bran oil utilization in international and domestic market could be due to its compatibility with other vegetable oil as blending oil besides used for direct consumption (Garba et al., 2017) and due to its various health benefits and a cheap market price promoted as healthy edible oil among consumers (Nayik et al., 2015 and Garba et al., 2017).

\section{Way forward}

From recent past, literacy about health made tremendous change in food habits in human being. Edible oil takes paramount importance in Indian dietary system, the various studies conducted by the earlier workers on asserting ideal edible oil over the time indicated, rice bran oil as the best edible oil of plant origin and is gaining popularity among other traditionally used cooking oils because of its better cooking quality, prolonged shelf life and well-balanced fatty acid composition as well as the presence of many antioxidant components (Ali and Devarajan, 2017). Consumption of rice bran oil has been shown to have innumerable health benefits in overcoming present day disease like antihypertensive, antidiabetic, lipid-lowering and anti-carcinogenic properties (Wilson et al. 2000; Wilson et al. 2007; Most et al. 2005; Salar et al. 2016; Dhavamani et al. 2014; Devarajan et al. 2016 and Szcześniak et al. 2016) over other vegetable oils of today's oil market.Indicating that, there is a wide market opening for rice bran oil in India as well as in overseas. On the other end, shrinking capabilities of principle edible oil crops exerting huge pressure on rainfed agro-ecosystem to produce more and more and as a result it is impairing resource base. In this situation, exploitation of rice bran as a complimentary source of vegetable oil would sustain the countries vegetable oil economy. To unlock the complete potentiality of rice bran oil in India with available raw material,

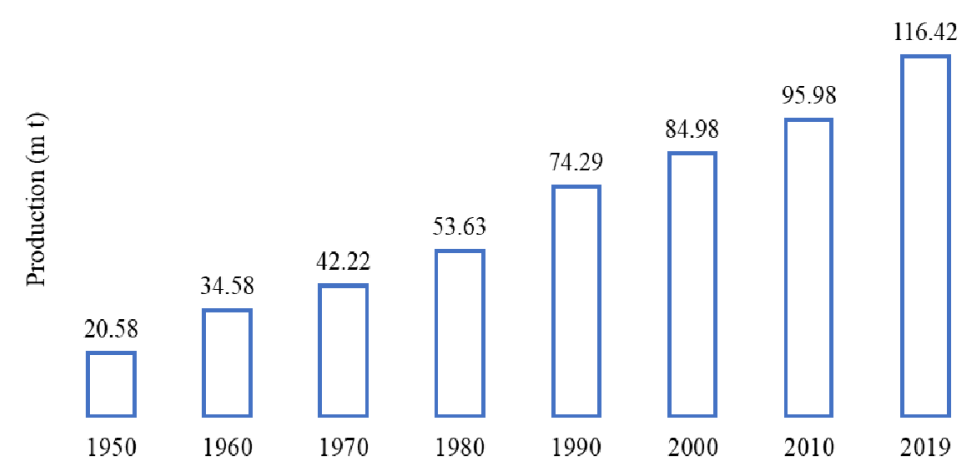

Source: Directorate of Economics and Statistics, GOI (2020).

Fig 3: Growth in rice production over the period of time in India. 
as per the opinion of Solvent Extractors' Association (2019). Oil expelling infrastructure needs to be strengthened with more efficient extraction protocols. If these key prerequisites are assured, rice barn oil would emerge as a silver lining of edible oil economy of India.

\section{CONCLUSION}

India is one among major rice producing country in the world. Milling results in huge amount of rice bran and essentially it contains upto $24 \%$ of valuable high-quality edible oil, which is rich with desirable fatty acid composition and antioxidant profile. With distressed vegetable oil economy in India due to excessive dependence on vegetable oil import, this is high time to make best possible benefits from raw material available within India. If potentiality of rice bran oil is unlocked with suitable strategies, it could emerge as a potential indigenous source of vegetable oil rather going as waste.

\section{REFERENCES}

Agricultural Statistics at a Glance (2019). Government of India Ministry of Agriculture and Farmers Welfare Department of Agriculture, Cooperation and Farmers Welfare Directorate of Economics and Statistics. pp-1-502. India does not even produce half of its edible oil requirements, mainly due to rainfed conditions, high seed cost, smallholding with limited resources, low seed replacement rate, and low productivity.

Ali, A. and Devarajan, S. (2017). Nutritional and Health Benefits of Rice Bran Oil. Springer International Publishing AG 2017 135 A. Manickavasagan et al. (eds.), Brown Rice, DOI 10.1007/978-3-319-59011-0_9

Amarasinghe, B.M.W.P.K., Kumarasiri, M.P.M., and Gangodavilage, N.C. (2009). Effect of method of stabilization on aqueous extraction of rice bran oil. Food and Bioproducts Processing. 87(2): 108-114.

Bernardi, D.S., Pereira, T.A., Maciel, N.R., Bortoloto, J., Viera, G.S., Oliveira, G.C., and RochaFilho, P.A. (2011). Formation and stability of oil-in- water nanoemulsions containing rice bran oil: in vitro and in vivo assessments. Journal of Nanobiotechnology. 9: 44

Chatha, S.A.S., Hussain, A.I., Zubair, M., and Khosa, M.K. (2011). Analytical characterization of rice (Oryza sativa) bran and bran oil from different agro- ecological regions. Pakistan Journal of Agricultural Sciences. 48(3): 243-249.

Devarajan, S., Chatterjee, B., Urata, H., Zhang, B., Ali, A., Singh, R., Ganapathy S (2016). A blend of sesame and rice bran oils lowers hyperglycemia and improves the lipids. The American Journal of Medicine. 129(7): 731-739

Dhavamani, S., Rao, Y.P.C., Lokesh, B.R. (2014). Total antioxidant activity of selected vegetable oils and their influence on total antioxidant values in vivo: a photo chemiluminescence based analysis. Food Chemistry. 164: 551-555.

Dunford, N.T. and King, J.W. (2000). Phytosterol enrichment of rice bran oil by a supercritical carbon dioxide fractionation technique. Journal of Food Science. 65(8): 1395-1399.

Fan, H.Y., Sharifudin, M.S., Hasmadi, M. and Chew, H.M. (2013). Frying stability of rice bran oil and palm olein. International Food Research Journal. 20(1): 403-407.
Garba, U., Singanusong, R., Jiamyangyuen, S., and Thongsook, T., (2017). Extraction and utilization of rice bran oil: A review. Proceedings of the $4^{\text {th }}$ International Conference on Rice Bran Oil 2017 (ICRBO 2017) Rice Bran Oil Application: Pharma-Cosmetics, Nutraceuticals and Foods 24-25 August 2017. pp- 1-13.

Gill, M.S., and Jat, M.L. (2006). Precision farming: Concept and realities in India. In: Advance in Agricultural Technology. Punjab Agricultural Management and Extension Training Institute, Ludhiana. pp. 155-164.

GOI, (2020). Agricultural Statistics at a Glance (2019). Directorate of Economics and Statistics, Government of India pp-1335 at: www.agricoop.nic.in and http:// eands.dacnet.nic.in

Huang, W.W., Wang, W., Li, J. lie and Li, Z.H. (2013). Study on the preparation process of rice bran oil by the ultrasonic enzymatic extraction. Advance Journal of Food Science and Technology. 5(2): 213-216.

Ju, Y.H., and Vali, S.R. (2005). Rice bran oil as a potential resource for biodiesel: A review. Journal of Scientific and Industrial Research. 64(11): 866 -882.

Lakkakula, N.R., Lima, M. and Walker, T. (2004). Rice bran stabilization and rice bran oil extraction using ohmic heating. Bioresource Technology. 92(2): 157-161.

Loypimai, P., Moongngarm, A. and Chottanom, P. (2015). Impact of stabilization and extraction methods on chemical quality and bioactive compounds of rice bran oil. Emirates Journal of Food and Agriculture. 27(11): 849856.

Mahajan, G., Singh, K. and Gill, M.S. (2012). Scope for enhancing and sustaining rice productivity in Punjab (Food bowl of India). African Journal of Agricultural Research Vol. 7(42) 5611-5620, DOI: 10.5897/AJARx11.027

Market Analysis Report (2019). Rice Bran Oil Market Size, Share and Trends Analysis Report by Application (Food and Beverage, Nutraceutical, Animal Feed), By Distribution Channel (Offline, Online), By Region, And Segment Forecasts, 2019 - 202. pp-1-80. Retrieved from https:/ /www. grandviewresearch.com/industry-analysis/ricebran-oil-market.

Matouk, A.M., El-Kholy, M.M., EISadany, M. and Hendawy, Y.T. (2009). Rice bran oil extraction using an expeller machine. Journal of Agricultural Engineering. 26(1): 324-342.

Most, M.M., Tulley, R., Morales, S., Lefevre, M. (2005). Rice bran oil, not fiber, lowers cholesterol in humans. The American Journal of Clinical Nutrition. 81: 64-68.

Nayik, A.G., Majid, I., Gull, A., and Muzaffar, K. (2015). Rice bran oil, the future edible oil of India: A mini Review. Rice Research: Open Access. 3(4): 4-6.

NMOOP (2018). Status paper on oilseeds. Department of Agriculture, Cooperation and Farmers Welfare, New Delhi. http://nmoop. gov.in/Publication/Status_Paper.pdf

Patel, M. and Naik, S.N. (2004). Gamma-oryzanol from rice bran oil - A review. Journal of Scientific and Industrial Research. 63(7): 569- 578.

Salar, A., Faghih, S., Pishdad, G.R. (2016). Rice bran oil and canola oil improve blood lipids compared to sunflower oil in women with type 2 diabetes: a randomized, single-blind, controlled trial. Journal of Clinical Lipidology. 10(2): 299-305 
Sayasoonthorn, S., Kaewrueng, S. and Patharasathapornkul, P. (2012). Rice bran oil extraction by screw press method: Optimum operating settings, oil extraction level and press cake appearance. Rice Science. 19(1): 75-78.

Sharma, A.R. (2002). Edible rice bran oil consumer awareness programme. Rice bran oil promotion committee. Solvent Extractors Association of India, Mumbai.

Solvent Extractors' Association (2019). Import of Vegetable Oil https://seaofindia.com/category/statistical-update/importof-vegetable-oil/

Szcześniak, K.A., Ostaszewski, P., Ciecierska, A., Sadkowski, T. (2016) Investigation of nutriactive phytochemical-gammaoryzanol in experimental animal models. Journal Animal Physiol. Animmal Nutrition. (Berl) 100(4): 601-617

Uquiche, E., Jerez, M. and Ortiz, J. (2008). Effect of pretreatment with microwaves on mechanical extraction yield and quality of vegetable oil from Chilean hazelnuts (Gevuinaavellana Mol). Innovative Food Science and Emerging Technologies. 9(4): 495-500.
Wilson, T., Ausman, L., Lawton, C., Hegsted, D., Nicolosi, R. (2000). Comparative cholesterol lowering properties of vegetable oils: beyond fatty acids. The Journal of the American College of Nutrition 19(5): 601-607

Wilson, T.A., Nicolosi, R.J., Woolfrey, B., Kritchevsky, D. (2007). Rice bran oil and oryzanol reduce plasma lipid and lipoprotein cholesterol concentrations and aortic cholesterol ester accumulation to a greater extent than ferulic acid in hypercholesterolemic hamsters. The Journal of Nutritional Biochemistry. 18: 105-112

Zúñiga-Diaz, J.E. Reyes-Dorantes, A. Quinto-Hernandez, J. PorcayoCalderon, J. G. Gonzalez-Rodriguez, and L. MartinezGomez (2017). Oil Extraction from "Morelos Rice" Bran: Kinetics and Raw Oil Stability. Journal of Chemistry Volume 2017. Article ID 3837506, 9 pages https://doi.org/ $10.1155 / 2017 / 3837506$ 